\title{
TRACIONAMENTO DE INCISIVO CENTRAL SUPERIOR IMPACTADO COM APARELHO REMOVÍVEL: RELATO DE DOIS CASOS CLÍNICOS
}

\author{
IMPACTED UPPER CENTRAL INCISOR TRACTION WITH REMOVABLE APPLIANCE: TWO CLINICAL \\ CASE REPORTS
}

Paula Marcolin FURLANETTO $^{1}$; Eduardo Silveira Ferreira ${ }^{1}$; Karina Santos MUNDSTOCK ${ }^{1}$

1 Departamento de Cirurgia e Ortopedia, Faculdade de Odontologia

da UFRGS.

Correspondência:

Nome: Prof ${ }^{\mathrm{a}}$. Karina Santos Mundstock

Email: ksmundstock@gmail.com

Endereço: Ramiro Barcelos 2492, Porto Alegre, RS

\section{RESUMO}

Um dente impactado é definido como aquele que apresenta, radiograficamente, dois terços de sua raiz desenvolvida e não entra em processo eruptivo. Quando esta condição se estabelece na região anterior, compromete a aparência estética da criança, preocupando os pais e incentivando a procura por um tratamento ortodôntico. O tratamento pode ser feito através de diferentes aparatologias, fixas ou removíveis. Objetivo: relatar dois casos clínicos de tracionamento de incisivo central superior impactado com aparelho removível, os quais foram tratados na Disciplina de Ortodontia Clínica da Faculdade de Odontologia da UFRGS. Relato de caso: Em ambos os casos os pacientes eram do sexo masculino, encontravam-se em fase de dentição mista e buscaram atendimento tendo como queixa a ausência do incisivo central superior. O tratamento foi realizado através de tracionamento dos incisivos impactados em ambos os pacientes. O tracionamento foi realizado utilizando-se um aparelho removível superior com arco de Hawley modificado que foi usado como apoio para uso de elásticos intermaxilares que aplicavam força para fazer a extrusão dos incisivos. Conclusão: o tratamento da impactação dentária com tracionamento apoiado em aparelho removível foi bem sucedido e apresenta, como todo tipo de tratamento, vantagens e desvantagens. É função do cirurgião dentista optar pelo melhor tipo de aparelhagem levando em conta a avaliação das particularidades de cada paciente.

Palavras-chave: Incisivo. Impactado. Tração.

\begin{abstract}
An impacted tooth is defined as the one that presents, radiographically, two thirds of its root developed and doesn't erupt naturally. When this condition is established in the anterior region, compromises the aesthetic appearance of the child, concerning the parents and encouraging the search for orthodontic treatment. The treatment can be done using different types of appliances, fixed or removable. Objective: the aim of this study was to report two clinical cases of impacted upper central incisor, which were treated using a removable appliance in the Orthodontic Department of the Faculty of Dentitry at the Federal University of Rio Grande do Sul. Case report: In both cases, the patients were male, in the mixed dentition and their chief complain was the absence of the central incisor. The treatment was performed through traction of the impacted incisors in both reported cases. The traction of the incisors was done using an upper removable appliance with a modified Hawley arch which was used to support the intermaxillary elastics that applied a force to extrude the incisors. Conclusion: the treatment for tooth impaction with traction supported by a removable appliance was successful, and as any kind of treatment has advantages and disadvantages. It is the duty of the general practitioner to select the best type of appliance for the case considering the particular characterists of each patient.
\end{abstract}

Keywords: Incisor. Impacted. Traction. 


\section{INTRODUÇÃO}

Em circunstâncias normais um dente irrompe quando sua raiz, ainda em desenvolvimento, apresenta três quartos do seu comprimento final. Quando esse movimento ocorre com menor desenvolvimento radicular, trata-se de um dente irrompido prematuramente. Em contraponto, um dente que apresenta, radiograficamente, dois terços de sua raiz desenvolvida e não entra em processo eruptivo é um dente impactado. Quando esta condição se estabelece na região anterior, compromete a aparência estética da criança, preocupando os pais e incentivando a procura ao tratamento ortodôntico ${ }^{1,2}$.

Segundo Becker ${ }^{1}$, a etiologia da impactação dentária pode ser dividida em dois grupos: de causas obstrutivas e de causas traumáticas. Dentre os fatores etiológicos obstrutivos estão os dentes supranumerários, os odontomas e a posição ectópica do germe dentário. Fazem parte da etiologia traumática a obstrução decorrente de reparação de tecido mole, a dilaceração, o desenvolvimento radicular interrompido e a intrusão traumática aguda. A impactação pode causar atrasos eruptivos. Suri et al. ${ }^{3}$ sugerem uma maneira de classificar a erupção dentária retardada, distinguindo os fatores etiológicos entre locais, sistêmicos e genéticos. São exemplos de fatores etiológicos locais a perda prematura de dentes decíduos, deficiência de comprimento do arco, anquiloses e a exposição à radiação X. Alguns dos fatores etiológicos sistêmicos citados são: infecção pelo vírus HIV, paralisia cerebral, nascimento prematuro, deficiência nutricional e distúrbios endócrinos. Já a etiologia genética está relacionada com a presença de síndromes.

$\mathrm{O}$ atraso eruptivo, que pode ter a impactação como causa, é a condição mais comumente encontrada quando se trata de desvios na cronologia de erupção ${ }^{3}$. A presença de dentes supranumerários está intimamente relacionada com essa condição, sendo o fator etiológico mais comum para impactação dentária. Em seu estudo, Betts e Camilleri ${ }^{4}$ reuniram 47 pacientes portadores de impactação de incisivo superior e observaram que $47 \%$ deles apresentavam como fator etiológico presença de dentes supranumerários, enquanto que os outros $53 \%$ encontravam-se divididos entre as demais etiologias, como odontomas (9\%), dilacerações (9\%), má posição do germe dentário (12\%), apinhamento (4\%), cisto odontogenico calcificante (2\%) e trauma no decíduo precedente (2\%).

Quanto ao diagnóstico de dentes impactados, Becker ${ }^{1}$ explica que deve ser dividido em quatro momentos: a anamnese, que deve abordar histórico de traumatismos e a história médica do paciente; o exame clínico, atentando-se para sinais como inclinação incorreta dos dentes adjacentes ao espaço edêntulo que torna o espaço para erupção insuficiente; a palpação, que tem sua importância vinculada ao diagnóstico da dilaceração radicular e por fim o exame radiográfico, sendo a radiografia periapical a primeira etapa e a tomografia computadorizada de feixe cônico (TCFC) a opção mais vantajosa. De acordo com Valente et al. ${ }^{5}$ quando o fator da impactação é um dente supranumerário ou um odontoma, a imagem tridimensional é essencial.

O prognóstico para dentes impactados depende de diversos fatores, tais como idade do paciente, etiologia da impactação, localização do dente impactado e tipo de exposição cirúrgica realizada. Chaushu et al. ${ }^{6}$ se dedicaram a avaliar os fatores que afetam o prognóstico e o tempo de duração do tratamento cirúrgico-ortodôntico de incisivos centrais impactados. Foram examinados os registros de 60 pacientes tratados, somando um total de 64 incisivos centrais impactados. Foi observado que o sucesso do tratamento varia de acordo com a etiologia, podendo ocorrer falhas principalmente em casos de dilaceração radicular.

Diante do exposto, o presente trabalho tem como objetivo relatar o tratamento ortodôntico de dois casos clínicos que apresentavam um incisivo central superior impactado tratados com tracionamento apoiado em aparelhagem ortodôntica removível na Disciplina de Ortodontia e Ortopedia Clínica da FO UFRGS. 


\section{DESCRIÇÃO DO CASO}

CASO 1

\section{Avaliação Clínica Inicial}

Paciente do sexo masculino, nove anos de idade, procurou por atendimento ortodôntico tendo como queixa principal a ausência do incisivo central superior direito. A avaliação inicial revelou bom estado geral de saúde. Ao exame extraoral se observou um perfil convexo, simétrico e terços faciais proporcionais. $\mathrm{O}$ exame intraoral revelou que o paciente encontrava-se em fase de dentição mista; boa condição de higiene bucal;

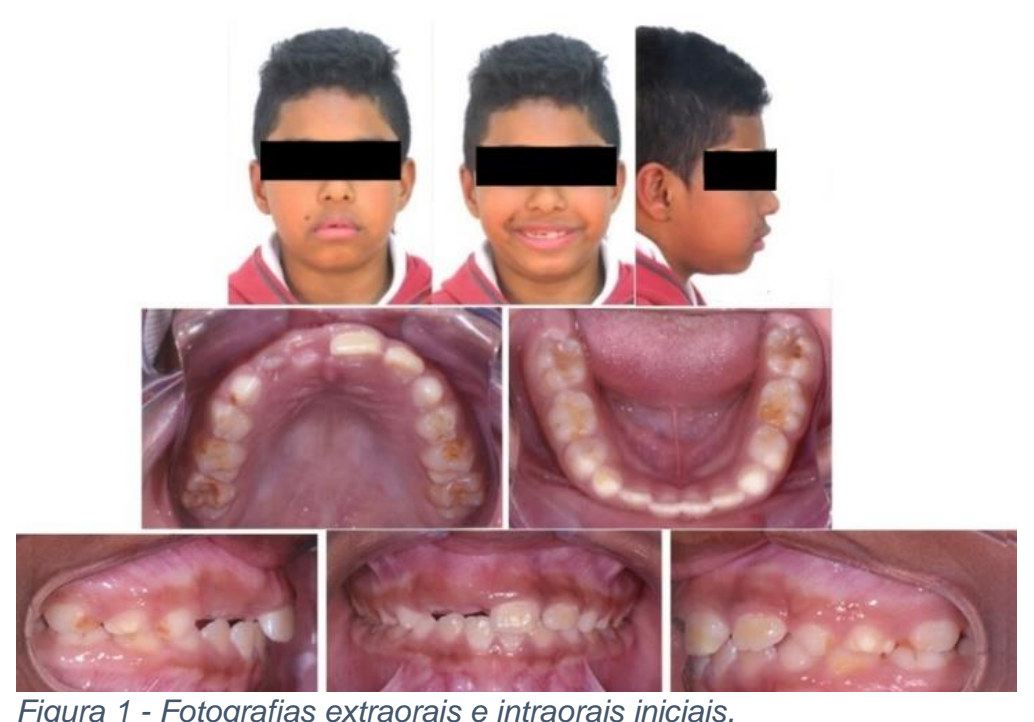
hipomineralizações dentais generalizadas; ausência do incisivo central superior direito; início eruptivo do incisivo lateral superior direito; caninos decíduos direitos e esquerdos em classe I; molares permanentes direito e esquerdo em classe I e pequeno desvio da linha média para o lado da ausência dentária (FIGURA 1). Ao final da consulta inicial, foi solicitada uma radiografia panorâmica.

\section{Avaliação Radiográfica}

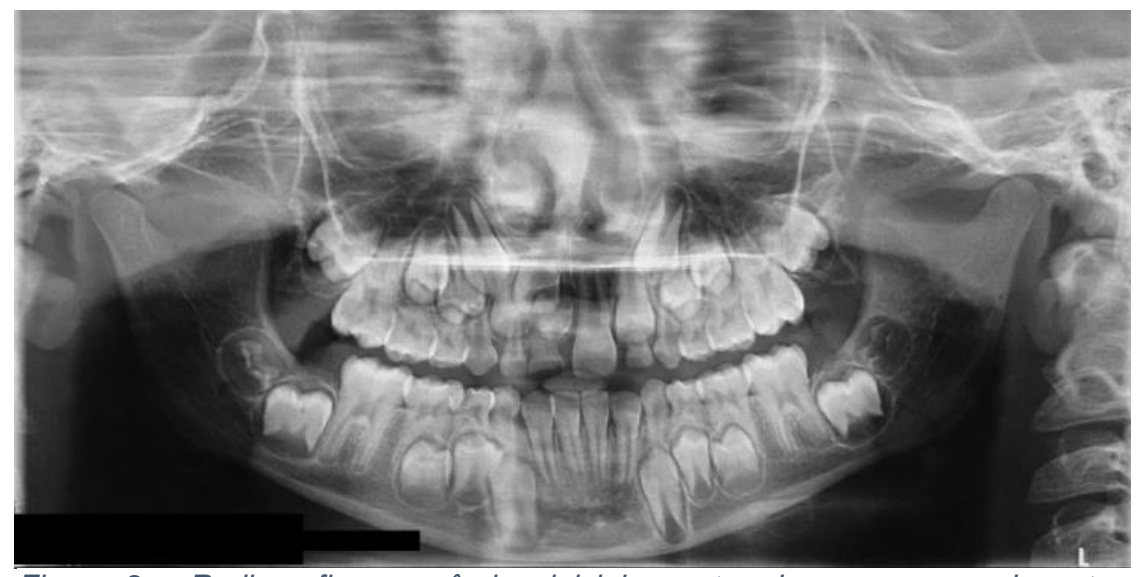

A avaliação do exame radiográfico panorâmico revelou área radiopaca, compatível com dente supranumerário associado ao incisivo central superior direito retido e diagnosticado como mesiodens, indicando a necessidade de intervenção cirúrgica (FIGURA 2).

Figura 2 - Radiografia panorâmica inicial, mostrando a presença de extra- Abordagem Cirúrgica numerário na região dos incisivos superiores.

A cirurgia para acesso ao dente impactado e remoção do dente supranumerário foi realizada no ambulatório de Cirurgia da Faculdade de Odontologia (FO-UFGRS), sob supervisão de professor desta área específica. Foi feita anestesia local, duas incisões relaxantes, remoção do dente supranumerário, remoção do folículo pericoronário do dente retido e controlada remoção de tecido ósseo, suficiente para expor a coroa e permitir um campo seco para colagem, com resina composta, do botão associado a fio de aço trançado. A ferida foi totalmente suturada, com pontos simples, e um segmento de fio deixado a nível gengival após sutura. $\mathrm{O}$ fio de aço trançado em torno do botão foi do tipo aciflex-0, e serviu como apoio para o tracionamento. É necessário ressaltar a importância da correta inclinação do fio de aço, que deve ser levemente palatina, para que a erupção do dente retido seja transalveolar ${ }^{7}$. Uma inclinação incorreta pode levar à reabsorção óssea vestibular, acarretando em recessão gengival e aumento do comprimento da coroa clínica do dente, prejudicando assim a estética do 
paciente. Após uma semana do procedimento cirúrgico o paciente foi liberado para iniciar o tracionamento.

\section{Tracionamento do Incisivo Central}

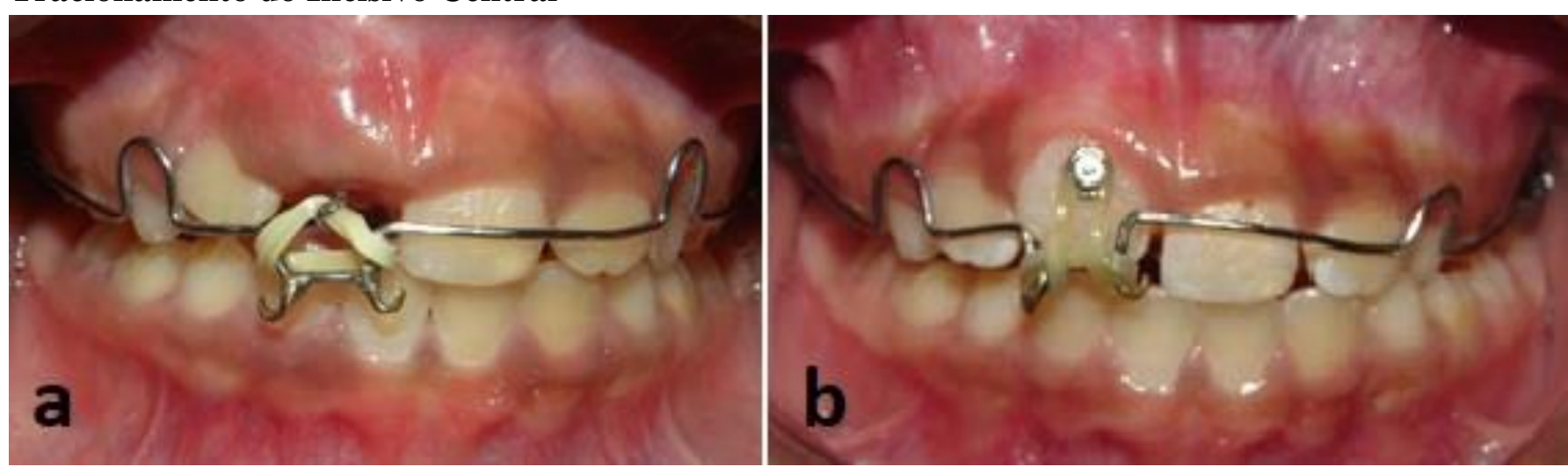

Figura 3- a: Início do tracionamento com aparelho removível com elástico intermaxilar; b: Incisivo superior direito já em boca.

Visto que não havia necessidade de obtenção de espaço na arcada dentária para erupção do incisivo impactado, o tracionamento pode ser iniciado logo após a remoção da sutura. Foi utilizado como ancoragem um aparelho removível com arco de Hawley modificado e ganchos soldados para encaixe de elásticos, ou seja, a força de tração - entre 50 a 100 gramas - foi aplicada através do uso de um elástico intermaxilar que era utilizado em tempo integral e trocados

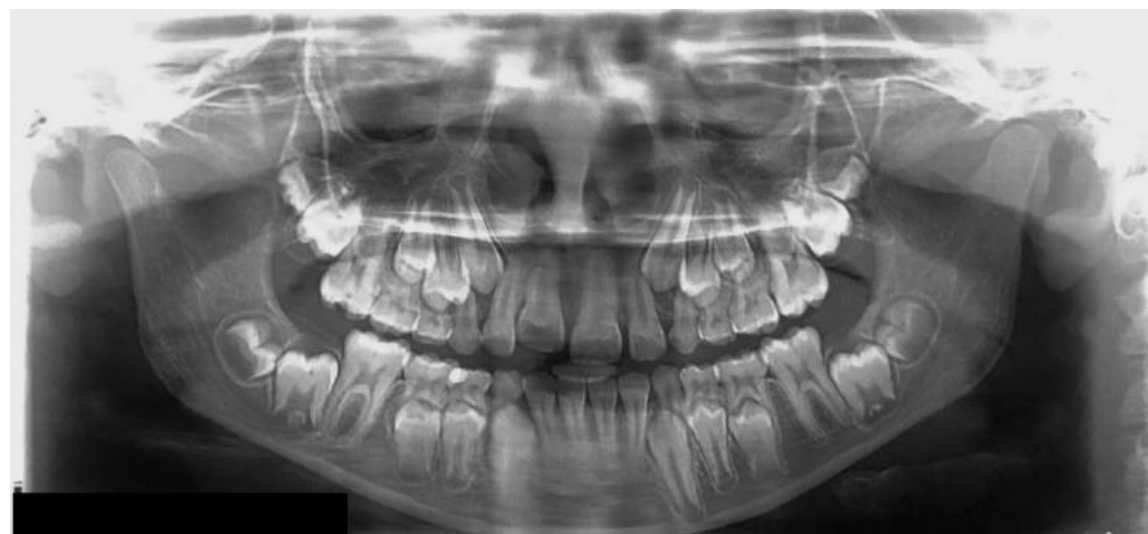

Figura 4 - Radiografia panorâmica de controle, após aproximadamente um ano de tracionamento.

diariamente pelo próprio paciente $(\text { FIGURA 3a) })^{8,9}$.

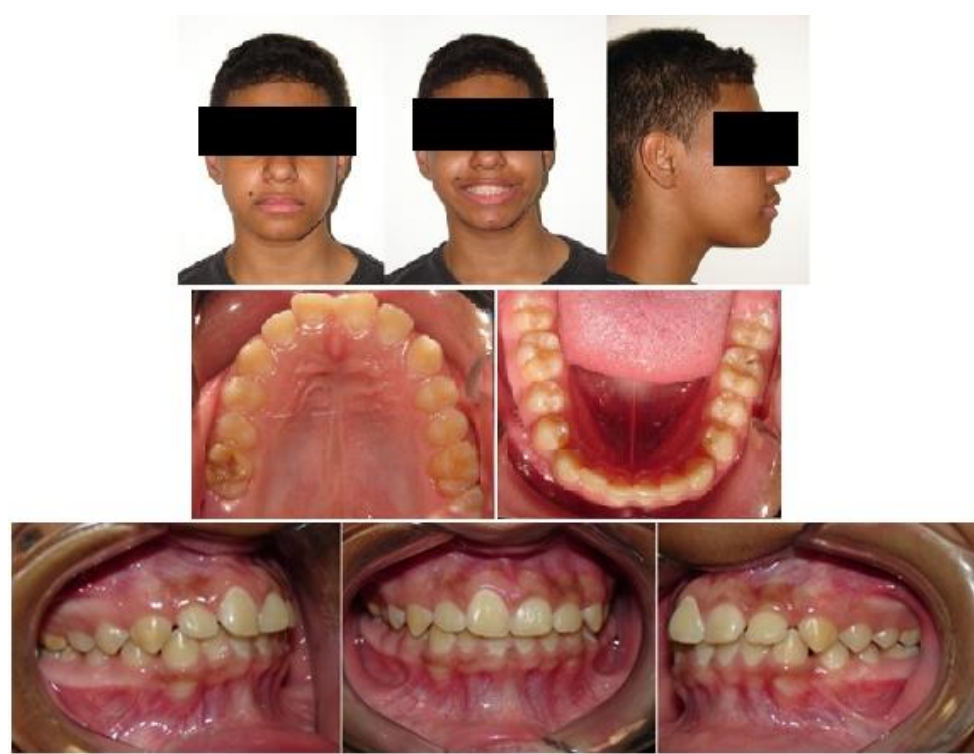

Figura 5 - Fotografias extraorais e intraorais finais, após o término das trocas dentárias.
As consultas foram realizadas a cada duas semanas para acompanhar o tracionamento do incisivo impactado.

Passadas aproximadamente quatro semanas da instalação do aparelho, o paciente retornou à consulta com o gancho utilizado para o tracionamento totalmente recoberto por tecido gengival, sendo necessária nova intervenção cirúrgica. Após aproximadamente nove meses de tracionamento foi iniciada a fase de contenção, que foi feita com um novo arco de Hawley e o paciente usou o aparelho por mais três meses. $\mathrm{O}$ aparelho foi removido e o incisivo central superior direito apresentava- 
se erupcionado e bem posicionado (FIGURA 3b).

No final do período de tratamento foi solicitada uma nova radiografia panorâmica (FIGURA 4). O paciente seguiu em acompanhamento até o fim da dentadura mista e estabelecimento da dentadura permanente.

Aos quatorze anos, o paciente foi reavaliado quanto à necessidade de tratamento ortodôntico corretivo para alinhamento dos dentes permanentes. As fotografias extraorais mostram um perfil convexo, simétrico e terços faciais proporcionais. $\mathrm{O}$ exame intraoral revelou linhas médias coincidentes; presença de alguns

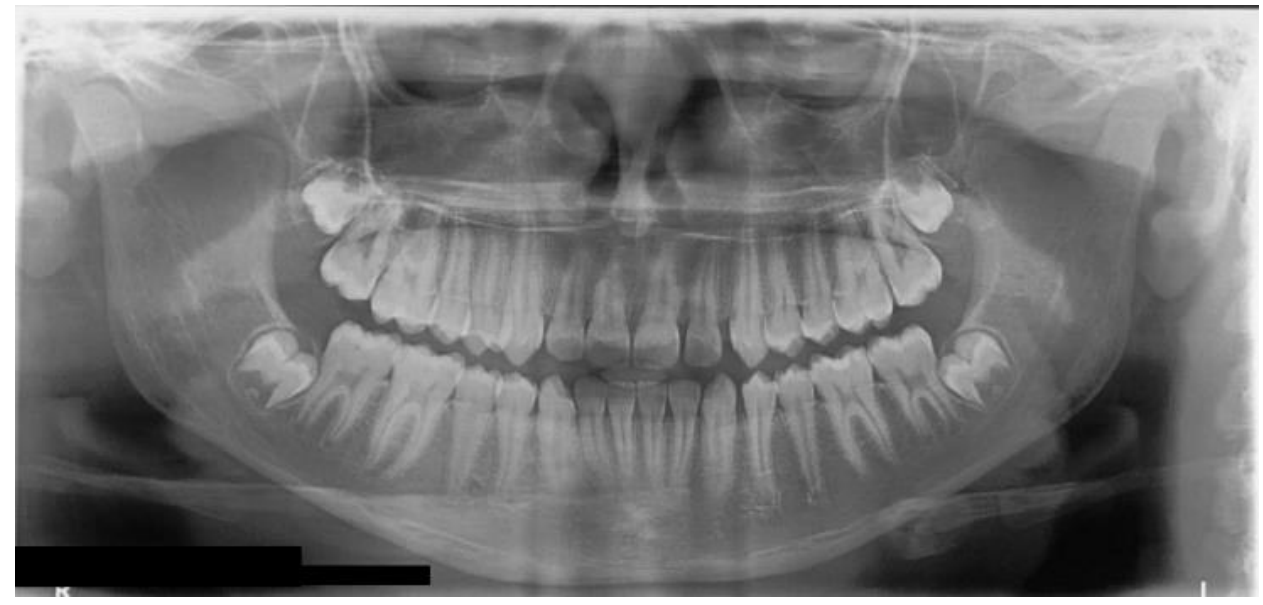

Figura 6 - Radiografia panorâmica final. diastemas, tanto no arco superior como no arco inferior; pequeno apinhamento na região anterior inferior e relação molar de classe I. (FIGURA 5)

Ao final da consulta foi solicitada uma nova radiográfica panorâmica (FIGURA 6). O exame da radiografia panorâmica ilustra uma condição compatível com a idade do paciente, o qual será acompanhado anualmente quanto à necessidade de exodontia dos terceiros molares. Embora seja possível atingir melhores resultados estéticos e funcionais com o tratamento ortodôntico corretivo, o paciente encontrava-se satisfeito com sua condição dentária e deixou claro que não quer utilizar aparelhagem ortodôntica fixa.

\section{CASO 2}

\section{Avaliação Clínica Inicial}
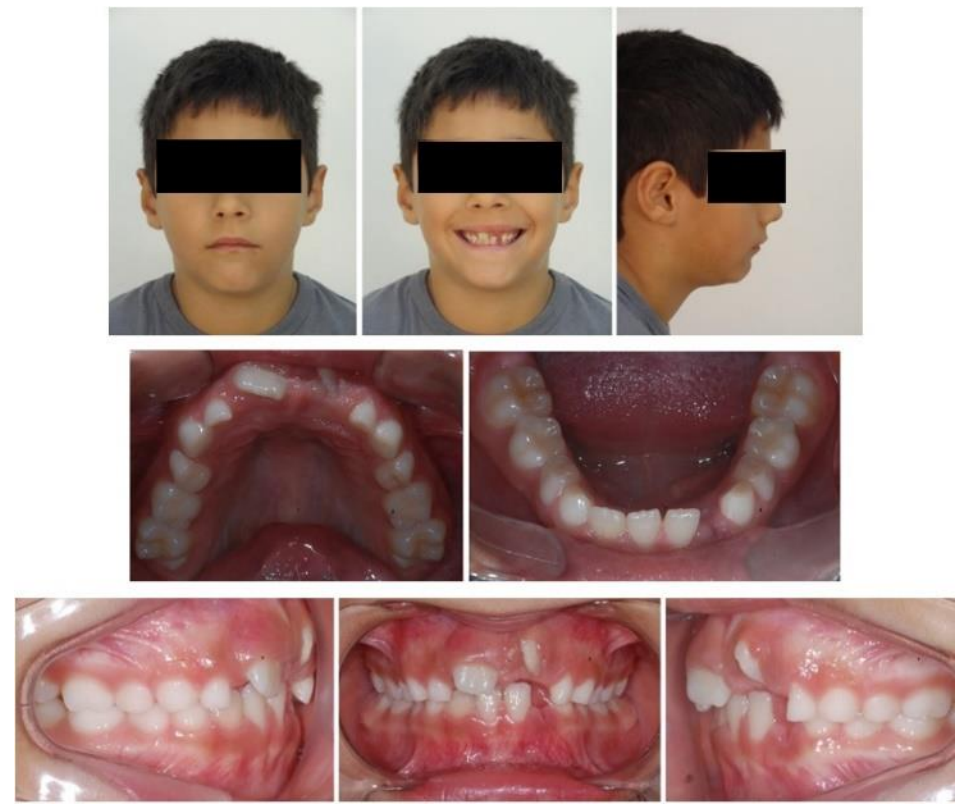

Figura 7 - Fotografias extraorais e intraorais iniciais
Paciente do sexo masculino, sete anos de idade, procurou a Disciplina de Ortodontia e Ortopedia Clínica da Faculdade de Odontologia da UFRGS tendo como queixa principal "que o incisivo central superior esquerdo não estava nascendo". Durante a entrevista dialogada foi relatado histórico de traumatismo (queda de bicicleta) associado à região do incisivo central superior esquerdo. A avaliação inicial revelou bom estado geral de saúde. Ao exame extraoral se observou um perfil reto, face ligeiramente assimétrica e terços faciais proporcionais. $\mathrm{O}$ exame intraoral revelou que o paciente encontrava-se em fase de dentição mista, boa condição de higiene bucal; incisivo central superior esquerdo parcialmente erupcionado, girovertido e em 
infraversão; incisivo central superior direito em processo de erupção; caninos decíduos direitos e esquerdos em classe I; molares permanentes em classe I e pequeno desvio da linha média (FIGURA 7). Ao final da consulta inicial, foi solicitada uma documentação ortodôntica.

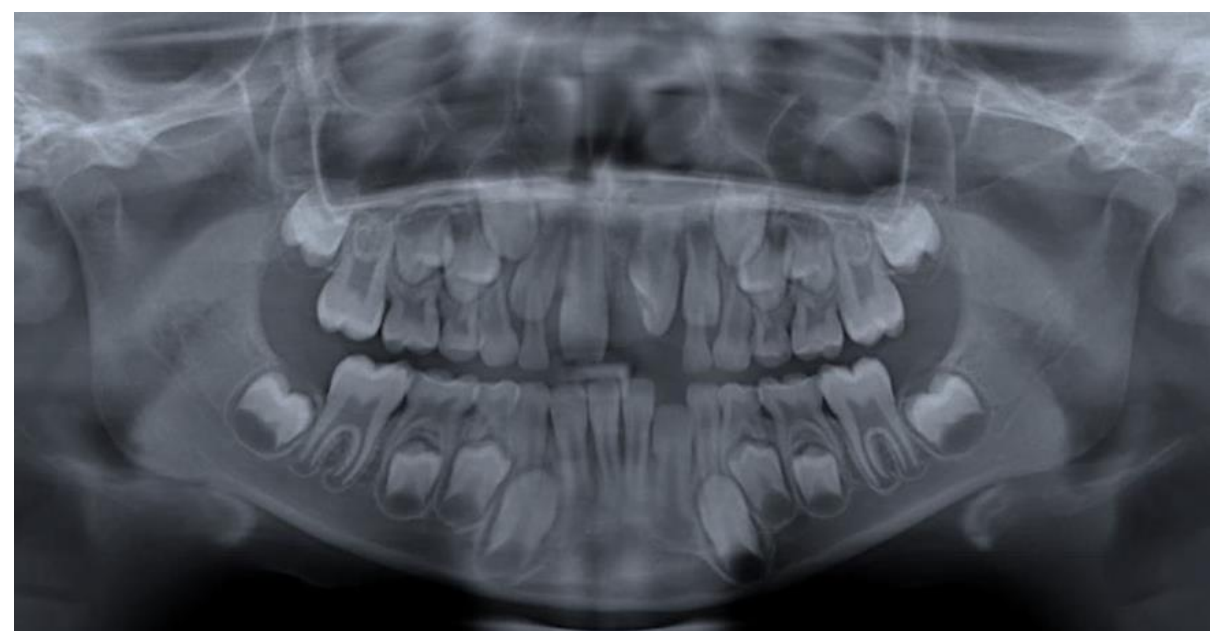

\section{Avaliação Radiográfica}

Ao exame radiográfico panorâmico e periapical iniciais não foi observada presença de nenhum fator obstrutivo para erupção do incisivo central superior esquerdo (FIGURAS 8 e 9).

Figura 8 - Radiografia panorâmica inicial.

\section{Tracionamento do Incisivo Central}

Não havendo necessidade de intervenção cirúrgica, o tracionamento do incisivo central superior esquerdo pode ser iniciado logo após a consulta de moldagem para confecção do aparelho removível que tinha um arco de Hawley modificado com ganchos soldados. Na consulta de entrega do aparelho foi feita a colagem do botão na face vestibular do incisivo central superior esquerdo e iniciou-se o tracionamento com uso de elásticos intermaxilares. A força de tração utilizada esteve entre 50 a 100 gramas. ${ }^{8,9} \mathrm{O}$ paciente

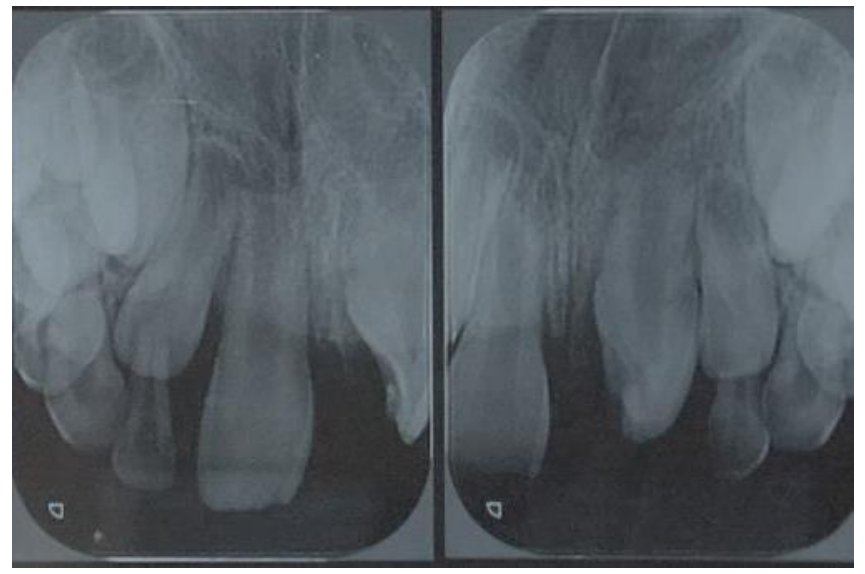

Figura 9 - Radiografias periapicais iniciais dos incisivos centrais superiores. foi orientado a utilizar o aparelho em tempo integral, removendo apenas para alimentação e higiene bucal. As consultas eram realizadas a cada duas semanas para acompanhar o tracionamento do incisivo impactado. Foram feitas fotografias para controle e acompanhamento do caso aos dois e seis meses de tracionamento (FIGURAS 10a e 10b). Passados oito meses de tratamento de tracionamento o botão foi removido, o tracionamento foi finalizado e uma nova moldagem foi feita para confecção de um novo arco de Hawley para contenção e movimentação do incisivo central superior esquerdo que encontrava-se com uma pequena giroversão (FIGURA 10c).
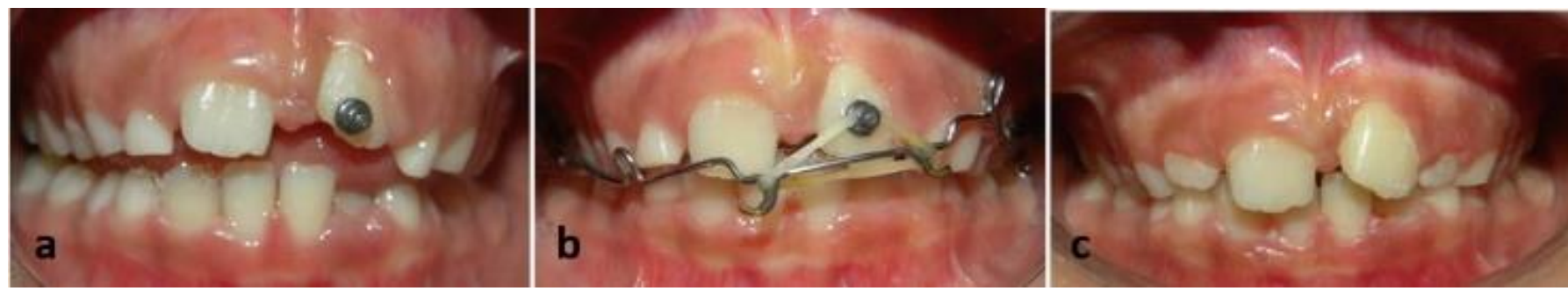

Figura 10 - Após dois (a) e seis meses (b) de tracionamento. Após oito meses de tratamento foi realizada a remoção do botão ortodôntico(c). 


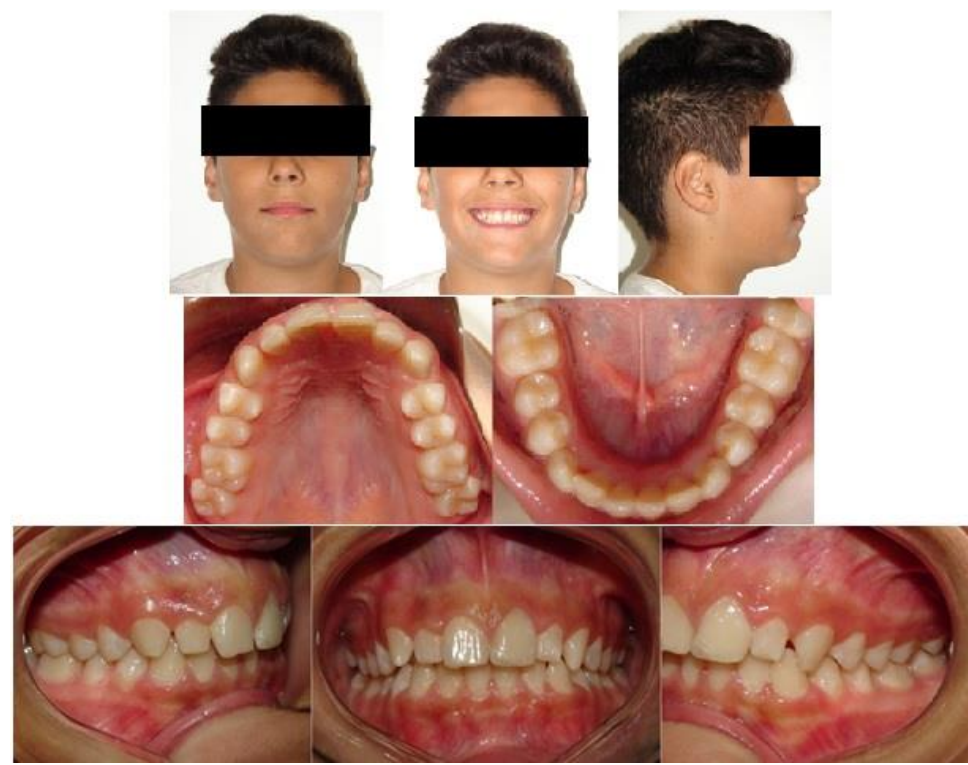

Figura 11 - Fotografias extraorais e intraorais finais.

Atualmente, o paciente encontra-se com 11 anos de idade, em fase de dentição permanente jovem completa. Foi feita uma reavaliação e as fotografias extraorais mostraram um perfil reto, simétrico, e terços faciais proporcionais. Ao exame intraoral se observou leve desvio da linha média para direita, presença de diastemas na região de caninos superiores, suave apinhamento inferior e relação molar de classe I do lado direito e esquerdo (FIGURA 11).

A radiografia panorâmica mais recente (FIGURA 12), realizada após três anos e dois meses de tratamento, quando o paciente se encontrava ainda em dentadura mista. Foi solicitada uma nova documentação ortodôntica para que o paciente continue o tratamento com ortodontia corretiva no curso de Especialização em Ortodontia da UFRGS.

\section{DISCUSSÃO}

Em ambos os casos, o fato dos pacientes se encontrarem em fase de dentição mista influenciou na escolha do tratamento de tracionamento com apoio em aparelho removível. Como explicam Mohammad-Rabei et al. $^{10}$, quando se realiza tratamento de tracionamento com aparelhagem fixa durante a fase de dentição decídua, as forças de tração

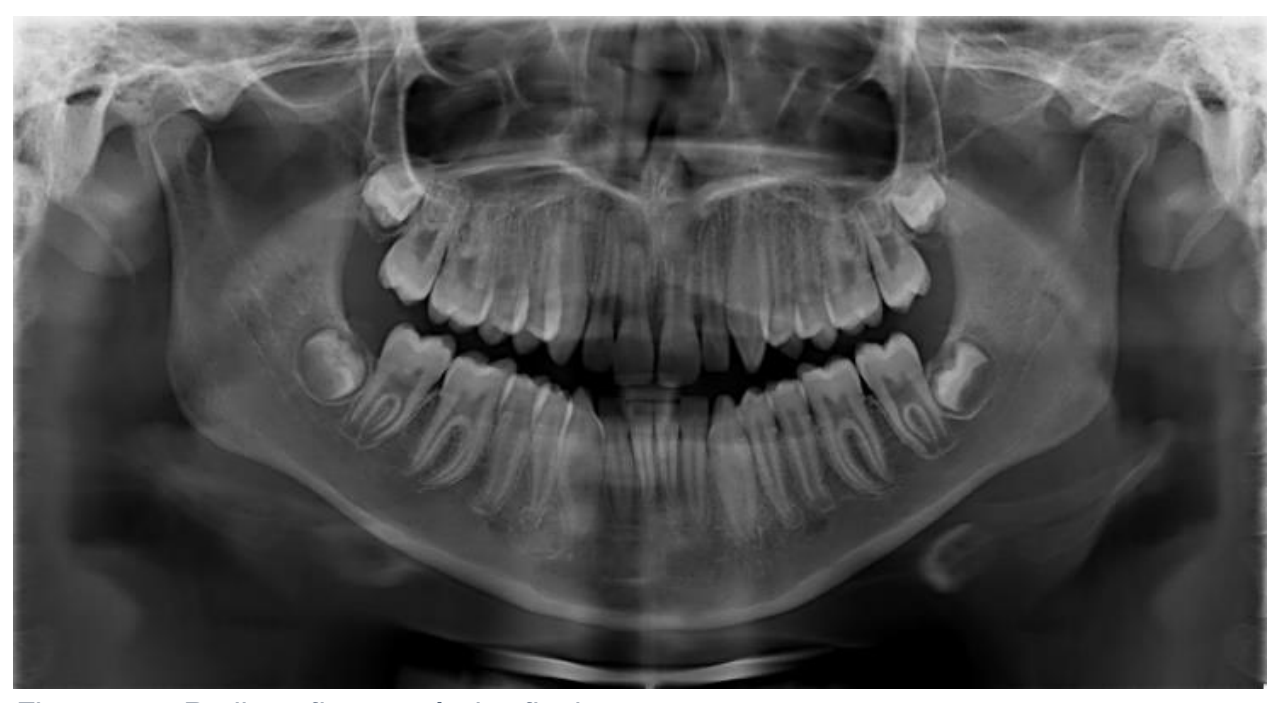

Figura 12 - Radiografia panorâmica final. são apoiadas somente nos dentes permanentes já erupcionados, normalmente incisivos e os primeiros molares permanentes. Por sua vez, a aparelhagem removível utiliza além dos dentes, também o palato duro e o próprio aparelho, diminuindo assim a probabilidade de efeitos adversos sobre os dentes. A maior facilidade da realização da higiene oral com uso de aparelho removível, principalmente nessa faixa etária, também é relevante para escolha do aparelho.

De acordo com Chaushu et al. ${ }^{6}$, o tempo de duração do tratamento cirúrgico-ortodôntico de incisivos centrais impactados é relativamente longo, podendo ser de até 2 anos, de acordo a altura inicial do dente impactado. O tempo de tracionamento foi menor que o previsto pelos autores, sendo de nove meses no caso 1 e de oito meses no caso 2.

Optar pelo tratamento com aparelho removível, nos casos apresentados, trouxe como vantagens a possibilidade de iniciar o tratamento imediatamente, ainda em dentição mista, sem depender da erupção dos dentes permanentes para a colagem de bráquetes. Como consequência, se produz um impacto positivo na autoestima e qualidade de vida do paciente, pelo favorecimento da condição estética. A menor 
probabilidade de efeitos adversos nos dentes permanentes e a maior facilidade para realizar higiene oral, em comparação com o aparelho fixo, também são vantagens desta modalidade de tratamento.

Depender da colaboração do paciente, normalmente criança ou pré-adolescente, para o uso do aparelho é uma desvantagem do tratamento com aparelho removível. A necessidade da troca de aparelho para ajuste final das posições dentárias, em uma segunda fase de tratamento com aparelho fixo pode ou não ser considerada uma desvantagem, já que em algumas circunstâncias não é necessária - como descrito no caso 1, onde mesmo com a possibilidade de realizar tratamento com aparelhagem fixa o paciente estava satisfeito com sua condição estética. É importante que o cirurgião-dentista tenha sensibilidade para perceber até que ponto essa segunda fase de tratamento tem significado para o paciente, cabendo ao paciente decidir se deseja ou não esta continuidade de tratamento.

\section{CONCLUSÃO}

A presença de um incisivo central superior impactado é uma condição que compromete fortemente a estética e a função da criança ou pré-adolescente, e, consequentemente, sua qualidade de vida, gerando ansiedade no paciente e na sua família quanto a uma solução.

Foram apresentados dois casos clínicos de impactação de incisivo central superior onde o tratamento com aparelho removível apresentou sucesso. Tratar casos de impactação dentária com tracionamento apoiado em aparelho removível apresenta, como todo tipo de tratamento, vantagens e desvantagens. É função do cirurgião dentista optar pelo melhor tipo de aparelhagem levando em conta a avaliação das particularidades de cada caso.

\section{REFERÊNCIAS}

1. Becker, A. Tratamento ortodôntico de dentes impactados. São Paulo: Livraria Santos, 2004.

2. Gron AM. Prediction of tooth emergence. J Dent Res.1962; 41(3):573-585.

3. Suri L, Gagari E, Vastardis H. Delayes tooth eruption: pathogenesis, diagnosis, and treatment. A literature review. Am J Orthod Dentofac Orthop. 2003; 126(4):432-445.

4. Betts A, Camilleri GE. A review of 47 cases of unerupted maxillary incisors. Int J Paediatr Dent. 1999; 9(4):285-292.

5. 5.Valente NA, Soares BM, Santos EJC, Silva MBF. A importância da TCFC no diagnóstico e localização de dentes supranumerários. Rev Bras Odontol. 2016; 73(1):55-59.

6. Chaushu S, Becker T, Becker A. Impacted central incisors: factors affecting prognosis and treatment duration. Am J Orthod Dentofac Orthop. 2015; 147(3):355-362.

7. Rizzatto S M D, Freitas M P M. Técnicas de colagem para erupção induzida ortodonticamente de incisivos retidos. Rev Ortod Gaucha. 2009; XIII(2):5-10.

8. Uematsu S, Uematsu T, Furuwasa K, Deguchi T, Kurihara S. Orthodontic treatment of an impacted dilacerated maxillary central incisor with surgical exposure and apicoectomy. Angle Orthod. 2004; 74:132-136.

9. Chandhoke T K, Agarwal S, Feldman J, Shah R A, Upadhyyay M, Nanda R. An efficient biomechanical approach for the management of an impacted maxillary central incisor. Am J Orthod Dentofac Orthod. 2014; 146(2):249-254.

10. Mohammad-Rabei E, Shamsi A, Farahani M. Treatment of impacted maxillary central incisor with removable appliance: a case report. Int J Med Pharm Case Reports. 2016; 8(2):2-6. 